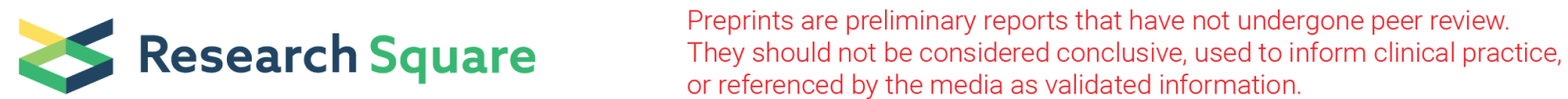

\section{Auditory icon alarms easier to identify than standard melodic alarms in a simulated intensive care setting}

\section{Richard McNeer \\ Danielle Horn \\ Christopher Bennett \\ Judy Edworthy \\ Roman Dudaryk}

\section{Video Abstract}

Keywords: alarm, auditory alarm, auditory icon, audible alarm, medical alarm, melodic alarm, intensive care unit, ICU, simulation, simulated, anesthesiology, accuracy, identification, response rate, fatigue, task load, usability, Perioperative Medicine, ASA, American Society of Anesthesiologists

Posted Date: September 20th, 2019

DOI: https://doi.org/10.21203/rs.2.15095/v1

License: (c) (i) This work is licensed under a Creative Commons Attribution 4.0 International License. Read Full License 


\section{Abstract}

Accurate identification of medical alarm sounds can be life-saving, but current standard alarms are difficult to learn. One issue is that these alarms, despite having different melodies, possess highly similar tonal qualities. This makes it hard to distinguish, for example, an alarm indicating an abnormal heart rate from one denoting abnormal oxygen saturation. To ease interpretation, researchers have developed new auditory icon alarms. These real-world sounds are associated with the processes they represent, such as the sound made by pills rattling in a bottle to indicate a drug administration issue or the sound of assisted breathing to denote abnormal ventilation parameters. The intuitive reaction to such sounds should make the icon alarms easier to identify than standard alarms, creating new possibilities to improve patient safety. The team tested the usability of the icons in a simulated intensive care unit. Anesthesia providers were randomized to a current standard or icon group and then asked to review a brief presentation introducing the different alarm sounds. After the presentation, alarms were played, and the subjects logged alarm types on a graphical user interface. Each subject went through two rounds of testing, spaced one week apart. At the end of the second session, they completed two validated psychometric instruments to assess perceived fatigue and task load, as well as an exit survey evaluating the practicality of the alarms. The researchers found that the participants identified the auditory icons more accurately and quickly than standard alarms. Although identification accuracy varied with alarm category, those in the icon group were 26 times more likely to correctly identify an alarm than those in the current standard group. They also responded to the alarms an average of 3 seconds faster. Career training level had no effect on subject performance, demonstrating the broad usability of the icons. The exit testing showed that the subjects in the auditory icon group also experienced less fatigue and lower levels of task load than those in the current standard group. They also reported finding the icon alarms more helpful than those listening to the standard alarms. Although more work is needed to improve the design of some individual icon alarms, these results support that highly intuitive recognition of medical alarm sounds is possible, even with minimal prior training. 